\title{
Intervenção Profissional na Educação Física Escolar: considerações sobre o trabalho docente
}

\author{
Jorge Both*
}

Juarez Vieira do Nascimento **

\begin{abstract}
Resumo: O presente ensaio aborda os principais problemas enfrentados no trabalho docente, mais especificamente dos professores de Educação Física da Educação Básica. O ambiente de trabalho nesta área tem favorecido o surgimento de doenças laborais, tais como Síndrome do Esgotamento Profissional, estresse, dependências químicas, doenças no aparelho fonador, entre outras. Deste modo, a necessidade de realização de novas investigações que abordem a qualidade de vida no trabalho e o estilo de vida dos docentes é apontada. Além disso, alerta-se para a necessidade dos problemas detectados serem considerados pelos gestores e pela comunidade escolar para favorecer a melhoria do ambiente da profissão docente.

Palavras-chave: Docentes. Educação Física. Condições de Trabalho. Doença. Satisfação no Emprego.
\end{abstract}

\section{INTRODUÇÃO}

$\mathrm{Na}$ área da Educação Física escolar tem predominado a realização de investigações que abordam os aspectos pedagógicos, considerados de suma importância para a melhoria da intervenção profissional. Contudo, as pesquisas sobre o trabalho docente, mais especificamente de suas relações com o ambiente de trabalho e suas interferências na vida do professor, vêm aos poucos despertando a atenção dos investigadores.

A qualidade de vida no trabalho, a Síndrome do Esgotamento Profissional, o mal-estar docente e o estresse profissional são alguns assuntos abordados pela comunidade acadêmica com tímido número de trabalhos, mas com repercussão bastante grande entre os pesquisadores e os professores da educação básica.

* Mestre em Educação Física pela Universidade Federal de Santa Catarina. Professor da Rede Municipal de Ensino de Florianópolis. Florianópolis, Santa Catarina, Brasil. E-mail: jorgeboth@yahoo.com.br

** Professor Doutor do Departamento de Educação Física do Centro de Desportos da Universidade Federal de Santa Catarina. Florianópolis, Santa Catarina, Brasil. E-mail: juarezvn@cds.ufsc.br 
O trabalho constitui a base de sustentação da vida das pessoas, tornando-se o centro principal dos interesses humanos (HOPF, 2002). De fato, esta situação foi ocasionada pela revolução industrial (CASTRO, 2005), a qual modificou toda a sociedade. Esta mudança foi marcante pelo surgimento de instituições organizadas burocraticamente, com tempo e funções determinadas, assim como organogramas rigorosos de cargos que, até então, não existiam na sociedade.

No contexto do magistério, observa-se que a profissão docente está frequentemente vinculada ao sacerdócio, tanto no passado quanto nos dias de hoje. Esta analogia não é difícil de ser construída, uma vez que os sacerdotes do século XIX acumulavam também a função do professorado. Esta perspectiva fez com que a profissão docente não fosse atrelada ao proletariado nem à burguesia, mas ocupasse outro patamar entre essas duas classes (NÓVOA, 1995a; NÓVOA, 1995b).

Ao considerar as mudanças que ocorreram nos últimos anos, Nóvoa (1995b) confirma que a profissão docente não sofreu alterações substanciais quando comparada com outras funções laborais. Um dos fatores apontados que justificam esta situação deve-se ao fato de que a classe docente é uma das maiores da sociedade contemporânea, porém com difícil organização sindical. Sobre este assunto, o autor comenta:

\begin{abstract}
A afirmação profissional dos professores é um percurso repleto de lutas e conflitos, de hesitações e de recursos. O campo educativo está ocupado por inúmeros actores (Estado, Igreja, famílias, etc.) que sentem a consolidação do corpo docente como uma ameaça aos seus interesses e projectos (NÓVOA, 1995b, p.21).
\end{abstract}

Para tornar a classe de professores mais organizada, há necessidade de pensar não apenas nos aspectos organizacionais, mas também na formação desse profissional. Nesta perspectiva, a formação docente tem sido concebida em duas etapas (inicial e continuada), sendo que uma complementa a outra e ambas estão vinculadas ao desenvolvimento profissional. Pacheco e Flores (1999) destacam que os processos que auxiliam na formação de professores têm sido

Movimento, Porto Alegre, v. 15, n. 02, p. 169-186, abril/junho de 2009. 
objeto de análise dos investigadores que buscam melhor compreender o desenvolvimento profissional docente.

Além da aquisição e do desenvolvimento de competências na situação de trabalho, a formação continuada também objetiva a promoção de inovações educacionais. Para concretização deste processo, os docentes necessitam de determinada organização no contexto escolar, a qual compreende questões pessoais, profissionais e organizacionais. Enquanto que a questão pessoal corresponde ao autodesenvolvimento e à aquisição de status na sociedade, o contexto profissional está atrelado à progressão da carreira, à satisfação profissional, à valorização do currículo e ao sentimento de pertencer ao grupo profissional. Por fim, a questão organizacional busca a adequação das mudanças sociais, econômicas e tecnológicas do mundo que o professor deverá entender para ensinar (PACHECO; FLORES, 1999).

A perspectiva ambiental da profissão docente é esclarecida por Corrigan e Haberman (1990), os quais destacam que as características dos professores baseiam-se nos conhecimentos sobre os assuntos abordados em sala de aula, avaliação da qualidade do trabalho pedagógico, bem como da disponibilidade de recursos e de condições para o trabalho. Salienta-se que este conjunto de características sofre influências da sociedade, do estado, da universidade, dos colegas de magistério e da(s) escola(s).

Um aspecto destacado por Teodoro (1994) é que o magistério está sendo menos atrativo a cada dia, pelos problemas enfrentados, contribuindo com a ocorrência de "crise de identidade" na profissão, a qual resulta no mal-estar docente. Embora considere que os tempos de crise e de incertezas ocorram em várias profissões, o autor observou que a violência contra professores, as brigas administrativas, os baixos salários, os elevados níveis de estresse, a Síndrome do Esgotamento Profissional, entre outros fatores, têm justificado a necessidade urgente da mudança de visão da comunidade perante a profissão docente para que esta situação desagradável seja modificada.

Assim, o objetivo deste ensaio é discutir sobre os principais problemas enfrentados pelos professores de Educação Física, abordando também as patologias comumente adquiridas na carreira docente.

Movimento, Porto Alegre, v. 15, n. 02, p. 169-186, abril/junho de 2009. 
Embora a busca textual às bases de consulta da área tenha sido exaustiva, os temas foram abordados apenas de modo suficiente, sem pretender ser conclusivo na discussão efetuada nem tampouco busca-se propor soluções inovadoras.

\section{Problemas enfrentados na PROFISSÃo docente}

A profissão docente é uma das mais antigas da humanidade e, com o passar dos tempos, os professores foram obrigados a adquirir diferentes competências daquelas exigidas no início da profissão. Mas, em um ponto a profissão docente não mudou, o de revelar sentimento e afeto no ato de educar os alunos (LEMOS; CRUZ, 2005).

$\mathrm{O}$ trabalho docente caracteriza-se pelas relações interpessoais entre professores e alunos, nas quais os docentes têm as funções de orientar, ensinar, preparar e ministrar aulas, assim como avaliar os educandos. Além das atividades docentes envolverem frequentemente a crítica, a autocrítica e a responsabilidade do professor, em muitos casos, o docente realiza atividades de ensino na escola e tarefas administrativas em casa, tendo uma dupla (ou às vezes tripla) jornada de trabalho (LEMOS; CRUZ, 2005).

Apesar das inúmeras responsabilidades assumidas pelo profissional docente, Andrews (1993), generalizando a realidade do magistério nos continentes europeu e latino-americano, defende que o nível de satisfação profissional do professor de Educação Física pode aumentar de diferentes formas. Entre as oportunidades existentes no ambiente escolar, o autor evidencia os contatos profissionais agradáveis com alunos, colegas e pais; o gosto pelo conteúdo ministrado na disciplina; o prazer em trabalhar em ambientes agradáveis; os resultados positivos obtidos em equipes esportivas escolares; o reconhecimento de sua importância no ambiente de trabalho; o desenvolvimento de diversas tarefas durante a sua atuação e a possibilidade de assumir postos de visibilidade importantes na escola.

Por outro lado, o nível de satisfação profissional é afetado pela frequente falta de materiais didáticos, constituindo-se num dos principais fatores do mal-estar docente (ANDREWS, 1993). De

Movimento, Porto Alegre, v. 15, n. 02, p. 169-186, abril/junho de 2009. 
fato, a carência de materiais limita as oportunidades para mudança das atividades, prejudicando também a qualidade dos exercícios, principalmente para torná-los mais atrativos aos estudantes. Outro fator que tem provocado insatisfação profissional é o acréscimo considerável de responsabilidades a serem assumidas pelos professores na escola. Com o passar dos anos, tanto a família quanto a sociedade têm repassado à escola algumas de suas responsabilidades na formação de crianças e jovens.

A insatisfação de professores, na visão de Neves, Rodrigues e Sobral (1993), resulta das condições dos locais de ensino, dos problemas psicológicos causados pela profissão e pelo sentimento de culpa decorrente do insucesso no processo de ensino. Um aspecto destacado pelos autores é que boas condições de trabalho tendem a gerar maior segurança, melhor qualidade de ensino e maior satisfação profissional.

Com relação às instalações das aulas de Educação Física, Monteiro (1993) esclarece que as condições e os locais de trabalho dos docentes necessitam de uma política de investimento para permitir a sua viabilização em condições adversas. Assim, para facilitar o trabalho prático nas aulas de Educação Física, o autor apresenta três fatores que devem ser considerados: os dados climáticos, a pluviosidade e os ventos predominantes. Os dados climáticos justificam-se pela necessidade dos espaços das aulas serem agradáveis. A pluviosidade limita o tipo de instalação que deve ser utilizada durante as aulas. Os ventos predominantes devem ser analisados para que os prédios das escolas possam auxiliar na otimização dos espaços da aula de Educação Física.

Diante do fato das instalações escolares serem, frequentemente, inadequadas para a prática de atividades físicas, especialmente pela falta de condições de segurança, insalubridade e higiene pessoal após o exercício físico, torna-se importante que os professores apresentem sugestões referentes ao ambiente de trabalho da Educação Física na escola (MONTEIRO, 1996a; MONTEIRO, 1996b).

Entre os problemas enfrentados na profissão docente, alguns investigadores (ANDREWS, 1993; GATTI, 1997; DORMAN, 2003; LAPO; BUENO, 2003; NILAN, 2003; DELCOR et al., 2004; LÜDKE; BOING, 2004; SOUSA, 2004; BRAGGER et al., 2005;

Movimento, Porto Alegre, v. 15, n. 02, p. 169-186, abril/junho de 2009. 
CRUZ; LEMOS, 2005; LACAZ, 2005; LEMOS; CRUZ, 2005; CHIU et al., 2006; PORTO et al., 2006; REIS et al., 2006; CHIU; LAM, 2007; LEMOS, 2007) têm observado que há um crescente número de docentes estressados, devido à baixa remuneração, à falta de melhores condições de trabalho, à falta de relacionamento amigável com os alunos e à sobrecarga de trabalho. Os fatores climáticos, as condições materiais, a sociabilização entre professores e o ambiente de trabalho também têm sido objeto de estudo para melhor compreender o mal-estar docente.

Os problemas que interferem no trabalho docente não se reduzem à falta de melhores condições de trabalho e de remuneração inadequada. Ao investigar os fatores intervenientes da carreira docente, Garcia (1995) destaca também a burocratização do trabalho do professor, a proletarização e a intensificação do trabalho do professor, a progressiva feminização da profissão docente, o isolamento dos professores, a carreira docente plana e a profissão com riscos psicológicos.

A burocratização do trabalho do professor é justificada pelo autor devido ao fato das escolas possuírem uma organização hierarquizada, na qual os processos administrativos passam por várias instâncias para terem soluções. Assim, as tomadas de decisões são transformadas em problemas técnicos.

Enquanto que a proletarização do trabalho do professor caracteriza-se pela situação da classe dos professores pertencer à massa de trabalhadores que não possui o controle da instituição que rege o sistema educacional, a intensificação do trabalho docente compreende a pressão constante dos professores na busca de inovações educacionais. Mas, ao mesmo tempo, as instituições educacionais não apresentam condições de trabalho para que possa ocorrer esta busca, nem a sua devida operacionalização no ambiente escolar.

O aumento considerável de professoras atuando nas escolas é um dos aspectos apontados por Garcia (1995) e Carvalho (1996b) para identificar a progressiva feminização da profissão docente. Além disso, mesmo que não existam diferenças entre o gênero masculino e o feminino na intervenção profissional, a atuação docente na escola tem sido acompanhada por uma depreciação do trabalho feminino pela sociedade.

Movimento, Porto Alegre, v. 15, n. 02, p. 169-186, abril/junho de 2009. 
O isolamento dos professores ocorre devido ao fato dos docentes dedicarem muitas horas semanais de trabalho às escolas, nas quais há poucas trocas de experiências entre professores de uma mesma disciplina. No ofício do professor, apenas existe a troca de informações entre professor-aluno, diferentemente de outras profissões que podem ter relacionamentos profissionais durante a prestação de serviços.

A carreira docente é considerada "plana" por Garcia (1995), em razão de os docentes não terem incentivos frequentes para subir na carreira nem motivação para melhorar a sua condição de trabalho. Uma forma de motivar os docentes seria o pagamento de melhores salários.

Além desses fatores, a profissão docente apresenta riscos psicológicos, principalmente pelas possibilidades de acarretar estresse, ansiedade, mal-estar e esgotamento profissional. O mal-estar docente caracteriza-se pelas más condições psicológicas e sociais dos professores. Estas condições têm como fatores desencadeadores as características da escola, do professor, da carga de trabalho que envolve as tarefas burocráticas, as condições de trabalho, os relacionamentos pessoais com alunos, outros professores e funcionários, assim como o estresse.

No que diz respeito ao mal-estar docente em professores de Educação Física, Sousa (2004) realizou uma pesquisa com docentes portugueses a partir da qual apontou como principais dificuldades enfrentadas na área aquelas referentes às condições de estrutura organizacional da instituição, as condições de trabalho, a cultura da escola e os conteúdos do ensino. Por outro lado, a satisfação do professor após a aula está vinculada à compreensão dos objetivos do tema abordado e à satisfação dos alunos, bem como às características positivas da própria participação dos alunos.

Um aspecto evidenciado pelos docentes portugueses investigados é que a satisfação no trabalho está alicerçada nos seguintes fatores: cumprimento do plano de aula estabelecido, concretização dos objetivos, vivência pessoal da aula, êxito no processo educativo, satisfação dos alunos que têm maiores dificuldades, reconhecimento de que a aula foi educativa e a autopercepção do prazer de estar na aula (SOUSA, 2004).

Movimento, Porto Alegre, v. 15, n. 02, p. 169-186, abril/junho de 2009. 


\section{Patologias AdquiridAs Pela CLASSE docente}

Os professores têm ocupado um lugar de destaque no processo social e produtivo da sociedade, por realizarem atividades de assistência interpessoal, ou seja, atendem um grande número de pessoas repassando novas informações. O fato do professor ser responsável por um número grande de turmas, as quais têm, em muitos casos, acima de 30 alunos por turma, pode favorecer uma maior predisposição aos transtornos psicossociais do trabalho. Observa-se também que fatores físicos têm justificado o afastamento do ambiente de trabalho docente, como o pó de giz, que pode provocar irritações e alergias nas vias respiratórias; o uso demasiado do aparelho fonador, que pode gerar calosidade nas pregas vocais e a permanência por longos períodos em pé, que pode resultar em desconforto e dor (NEVES; RODRIGUES; SOBRAL, 1993; DELCOR et al., 2004; CRUZ; LEMOS, 2005; GRILLO; PENTEADO, 2005; LEMOS; CRUZ, 2005; PENTEADO; PEREIRA, 2007).

A sobrecarga de trabalho, de acordo com Lemos e Cruz (2005), Neves, Rodrigues e Sobral (1993) e Gasparini, Barreto e Assunção (2005), repercute negativamente na vida diária dos professores, provocando algumas enfermidades, como asma, otites, bronquites, cefaleias, conjuntivites, perda auditiva, depressão, estresse e Síndrome do Esgotamento Profissional.

De fato, as condições de trabalho podem ser os fatores desencadeadores das patologias encontradas em docentes, especialmente porque elas determinam e intensificam as cargas de trabalho. Sobre este assunto, Lemos e Cruz (2005) destacam que os professores sofrem influência de todas as categorias que compõem as condições de trabalho, destacando-se os fatores físicos (relacionados à temperatura, ventilação, umidade, ruído e iluminação), químicos (vinculados ao pó de giz e radiações solares), biológicos ou orgânicos (que são as condições de higiene do local de trabalho), mecânicos (correlacionados às instalações de trabalho, as quais, em muitos casos, são precárias), fisiológicos (vinculados ao esforço físico demasiado do trabalhador) $\mathrm{e}$ psíquicos (que são as tensões psicológicas da organização do trabalho).

Movimento, Porto Alegre, v. 15, n. 02, p. 169-186, abril/junho de 2009. 
A partir da análise das categorias das condições de trabalho docente, Lemos e Cruz (2005, p.27) concluem que, de modo geral, os professores "[...] têm produzido e intensificado as cargas de trabalho da atividade docente, contribuindo para o aumento dos riscos de agravos à saúde e de adoecimento".

No que diz respeito ao estresse e à Síndrome do Esgotamento Profissional, os fatores desencadeadores dessas patologias podem ser: a sobrecarga do trabalho, a insatisfação com as relações pessoais no ambiente de serviço, as dificuldades encontradas no desenvolvimento da carreira profissional, a busca e/ou a manutenção do status profissional (o qual é vinculado ao poder salarial), a novidade ou a variedade das tarefas desempenhadas no decorrer do trabalho e a ambiguidade da função docente (SOUSA, 1993; JIMENEZ; HERNANDEZ; GUTIERREZ, 2000; DORMAN, 2003; DELCOR et al., 2004; CRUZ; LEMOS, 2005; LEMOS; CRUZ, 2005; BAUER et al., 2006; CHIU et al., 2006; CHIU; LAM, 2007).

Em relação ao estresse, Rodrigues (1992) acrescenta que o indivíduo estressado pode ajustar a doença de duas maneiras. A primeira, por meio do ajuste ativo, quando o indivíduo expressa a mudança do seu estilo de vida e pede, voluntariamente, o afastamento ou o remanejamento de suas funções. A segunda, por meio de ajuste passivo, ocorre quando a pessoa deprecia o trabalho, consequentemente, não o considera mais como envolvente, pratica o absenteísmo e adquire facilidade de contrair outras enfermidades.

Entre os indicadores frequentemente empregados para detectar se o indivíduo está estressado, Rodrigues (1992) destaca a necessidade de observar se há consumo de drogas, queda de eficiência, faltas repetidas, insegurança, sobrecarga no trabalho, consumo exagerado de medicamentos e surgimento ou agravamento de doenças.

Diversos estudos epidemiológicos realizados com professores têm destacado a existência de associação entre aspectos psicossociais do trabalho docente e a prevalência de distúrbios psíquicos - normalmente os professores com trabalho de alta exigência apresentam prevalência 1,5 vezes maior que os colegas com trabalho de baixa exigência

Movimento, Porto Alegre, v. 15, n. 02, p. 169-186, abril/junho de 2009. 
(PORTO et al., 2006); as condições de trabalho afetam a saúde mental dos professores, provocando desgastes psicológicos (DELCOR et al., 2004); fatores psicológicos (alto nível de estresse no trabalho) contribuem para o desenvolvimento de dor de cabeça (CHIU et al., 2006; CHIU; LAM, 2007); prevalência elevada de queixas de cansaço mental e nervosismo entre docentes (REIS et al., 2006).

$\mathrm{Na}$ investigação sobre o estresse em professores de Educação Física, Andrews (1993) considera o estresse uma pressão do ser humano, a qual advém de uma série de fatores externos. Além disso, acredita que determinado nível de estresse seja importante para qualquer pessoa, fazendo com que exista um mínimo grau de estimulação. Entretanto, a reação a esta doença só é negativa quando os fatores que a promovem são excessivos para a condição do indivíduo.

Os fatores do estresse podem ser agrupados em três categorias que compreendem as pressões ambientais, as fontes de tensão social e as dores pessoais. As pressões ambientais estão relacionadas à vida urbana (poluição do ar, ruído, trânsito, entre outras), alojamento (custos, localização, entre outras), comunicações (notícias ruins veiculadas rapidamente em emissoras de rádio ou TV) e superpopulação (em algumas cidades do mundo, este tema é bastante sensível). As tensões sociais estão vinculadas à burocracia, à autoridade, à responsabilidade, à discriminação e às diferenças culturais como religião e sexo. As dores pessoais estão associadas à idade, à personalidade, à doença e ao desejo de status (ANDREWS, 1993).

No caso específico dos professores de Educação Física, Andrews (1993) conclui que estão sujeitos a quatro formas do estresse: as pressões pessoais, que podem ocorrer em qualquer momento da vida; as pressões generalizadas, que a sociedade pode sofrer; os problemas relacionados ao ensino; e os problemas específicos dos professores de Educação Física. As pressões econômicas têm aumentado o estresse dos professores, pois os problemas financeiros, certamente, interferem no ajuste das contas públicas e pessoais. Estes problemas estão relacionados aos frequentes cortes de gastos na manutenção de escolas e na aquisição de material didático adequado para as aulas, assim como nos menores salários para os docentes.

Movimento, Porto Alegre, v. 15, n. 02, p. 169-186, abril/junho de 2009. 
Entre os problemas específicos dos professores de Educação Física, o autor destaca os ataques físicos e verbais contra os professores, causados pelos pais cujos filhos não têm sucesso nesta disciplina, ou em equipes esportivas vinculadas às escolas; a falta de educação dos alunos, gerada pelo fato dos pais não motivarem nem controlarem os filhos, fazendo com que a escola não consiga controlar muito os alunos; a falta de sentimento e de comprometimento com a profissão docente; o baixo status do professor perante a sociedade; a necessidade de trabalhar em mais de um local para ter um salário digno a fim de manter as mínimas necessidades familiares; a baixa satisfação com o trabalho e um sentimento de mal-estar perante a profissão.

Outra doença relacionada aos problemas encontrados pelos docentes nas escolas é a Síndrome do Esgotamento Profissional, também conhecida como Síndrome de Burnout ou Síndrome da Desistência. Esta patologia surge pelo confronto entre a realidade das condições de trabalho e o ambiente idealizado para a carreira docente. Santini e Molina Neto (2005), Bauer et al. (2006) e Carlotto e Pelazzo (2006) descrevem que o trabalhador experimenta um sentimento de exaustão e fracasso, resultando frequentemente em irritabilidade, fadiga, sobrecarga de trabalho, mau humor e rigidez nas atitudes.

As reações da Síndrome de Esgotamento Profissional, de acordo com Santini e Molina Neto (2005), podem ser distribuídas em quatro categorias: físicas (fadiga, insônia, dores musculares e de cabeça, perturbações gastrintestinais, problemas cardíacos e respiratórios, disfunções sexuais); comportamentais (irritabilidade, agressividade, tensão, intransigência, falta de iniciativa, aumento do consumo de substâncias nocivas à saúde, comportamento de risco, suicídio); psíquicas (falta de concentração, alterações da memória, solidão, depressão, desânimo) e defensivas (isolamento, sentimento de onipotência, desinteresse pelo trabalho, absenteísmo, ironia).

Apesar da diversidade das reações da Síndrome de Esgotamento Profissional, a pessoa que possui a doença, necessariamente, não apresenta todos os sintomas, devido às diversas etapas que a enfermidade possui (SANTINI, 2004a; SANTINI, 2004b).

Movimento, Porto Alegre, v. 15, n. 02, p. 169-186, abril/junho de 2009. 
Na pesquisa realizada com professores de Educação Física que se afastaram de suas obrigações laborais devido à Síndrome de Esgotamento Profissional, Santini e Molina Neto (2005, p.219) detectaram os seguintes problemas que levaram à doença:

[...] a) formação acadêmica insuficiente para enfrentar o choque com a realidade escolar; b) implantação de inovações e projetos políticos pedagógicos que minimizam a participação dos professores sujeitos; c) a multiplicidade de papéis sociais e profissionais exigidos e exercidos pelos professores de Educação Física nas escolas; d) ambiente de violência urbana e insegurança pessoal enfrentado pelos professores; e) conflitos nas relações interpessoais com os colegas de trabalho; f) condições materiais objetivas adversas aos exercícios do trabalho com a qualidade desejada pelo sujeito; e, g) a dificuldade de lidar, política e epistemologicamente, com críticas dirigidas por diferentes setores da comunidade escolar ao caráter e à contribuição da disciplina no desenvolvimento do currículo escolar.

De modo geral, as investigações sobre a Síndrome de Esgotamento Profissional e fatores associados a ela em professores destacam a exaustão emocional, a despersonalização e a diminuição da realização pessoal no trabalho. Além disso, denunciam os comportamentos agressivos dos alunos, o não alcance das expectativas elevadas dos pais e a baixa representatividade dos docentes nas decisões da escola como fatores desencadeadores do mal-estar docente que pode resultar no afastamento temporário ou permanente do trabalho docente (CARLOTTO; PALAZZO, 2006). Outros fatores desencadeadores dessa patologia são as elevadas exigências do trabalho docente que provocam distúrbios psíquicos (GASPARINI; BARRETO; ASSUNÇÃO, 2005; PORTO et al., 2006), interferem na saúde vocal, postural e mental (DELCOR et al., 2004) e diminuem o nível de satisfação profissional (REIS et al., 2006).

\section{CONSIDERAÇÕES FINAIS}

O trabalho docente da educação básica vem sofrendo uma depreciação. Baixos salários, professores desmotivados, más condições de

Movimento, Porto Alegre, v. 15, n. 02, p. 169-186, abril/junho de 2009. 
trabalho e relações pessoais fragilizadas no ambiente de trabalho são alguns fatores que contribuem para o surgimento de problemas patológicos em docentes e agravam ainda mais a depreciação desta função laboral.

Os professores de Educação Física, especialmente pelas suas características de trabalharem em ambientes abertos, vêm sofrendo outros problemas patológicos que não são ainda investigados de uma forma mais efetiva, como os cânceres de pele. $O$ estudo das relações entre as reais condições de trabalho docente e o possível adoecimento físico e mental dos professores constitui um desafio e uma necessidade para se entender o processo saúde-doença do trabalhador docente, bem como para encontrar possíveis associações ao afastamento do trabalho por motivos de saúde.

Embora as pesquisas que abordam a qualidade de vida no trabalho bem como o estilo de vida de professores são iniciativas promissoras para melhor compreender as condições de vida na carreira docente, há necessidade de continuação destes estudos para que os problemas detectados sejam considerados pelos gestores e pela própria comunidade escolar no sentido de garantir um ambiente de trabalho saudável na escola, de modo que favoreça os relacionamentos agradáveis e a autonomia mínima necessária para o desenvolvimento do trabalho do professor.

A preocupação em aumentar o nível de compreensão sobre as condições de vida do trabalhador docente, a partir dos pressupostos teóricos do paradigma da socialização ocupacional, pode ser um caminho viável para minimizar os efeitos dos problemas enfrentados na carreira docente. De fato, a socialização ocupacional baseia-se na organização do trabalho e nos fatores que influenciam as condições de vida do trabalhador. Embora as condições de trabalho moldem as ações docentes, tanto às ações individuais quanto as ações coletivas dos professores podem influenciar as condições de trabalho. Neste sentido, a socialização dos professores é influenciada pela história de vida, principalmente escolar, desde estudante da educação básica, passando pela formação inicial e continuada.

Movimento, Porto Alegre, v. 15, n. 02, p. 169-186, abril/junho de 2009. 
Um aspecto importante a destacar é a complexidade dos estudos desta natureza, visto que a socialização ocupacional contempla seis dimensões que possuem polos de variabilidade (CARVALHO, 1996a). Nomeadamente, a socialização pode ser afetada pela escala (coletiva ou individual), estrutura (formal ou informal), progressão (sequencial ou aleatória), temporalidade (fixa ou variável), apoio (modelador ou inexistente) e atitude (aceitação ou rejeição). Além disso, há momentos específicos de construção, consolidação e reconhecimento das identidades profissionais (DUBAR, 1997), os quais envolvem tanto aspectos relacionados à vida pessoal quanto à vida profissional, ao longo da carreira docente.

Outra iniciativa seria a investigação do nível de controle dos docentes sobre o próprio trabalho e sobre as demandas psicológicas oriundas do ambiente escolar, bem como das repercussões sobre a estrutura psíquica e orgânica dos professores. Além de aprofundar as demandas nas situações de trabalho (concentração, pressão do tempo, ritmo e volume das tarefas), haveria a preocupação em identificar as habilidades necessárias e as estratégias de enfrentamento de problemas como a Síndrome do Esgotamento Profissional.

Ao considerar que a organização do trabalho é uma instância determinante do grau de demanda psicológica e controle dos professores, recomenda-se que as ações de promoção à saúde no trabalho devem ser direcionadas às mudanças na organização do trabalho e não apenas às mudanças nos comportamentos individuais dos professores.

Movimento, Porto Alegre, v. 15, n. 02, p. 169-186, abril/junho de 2009. 
Professional Intervention at School's Physical Education: considerations about the teaching work

Abstract: This essay touch on the main problems faced in the teaching work. Most precisely, it deals with the professional practices of Physical Education teachers of basic education. The work's environment of such a subject has been favorable for the appearance of working diseases, such as the burnout syndrome, stress, chemical addiction, phonetic system infirmities, and so on. Thus, it is noticeable the necessity of new investigations about quality of life in the work, and life style of those teachers. In addition, this essay warms managers and the schooling community about the necessity of awareness on the detected problems in order to facilitate the improvement of the teacher's professional environment.

Keywords: Faculty. Physical Education. Working Conditions. Job satisfaction. Disease.

\footnotetext{
Intervención Profesional en la Educación Física Escolar: consideraciones acerca del trabajo docente

Resumen: El presente ensayo plantea los principias problemas enfrentados en el trabajo docente, tratándose especialmente de los profesores de Educación Física Básica. El ambiente de trabajo en esta área ha contribuido para el surgimiento de enfermedades laborales, tales como el síndrome del agotamiento profesional, estrés, dependencias químicas, enfermedades en el aparato fonador, entre otras. La necesidad de la realización de nuevas investigaciones que traten de la calidad de vida en el trabajo y el estilo de vida de los docentes es sobresaliente. Además, se alerta para la necesidad de especial atención por parte de los gestores y comunidad escolar con los problemas detectados, pues esto puede contribuir para la mejoría del ambiente de la profesión docente.

Palabras-claves: Docentes. Educación Física. Condiciones de trabajo. Satisfacción en el trabajo. Enfermedad.
}

\section{REFERÊNCIAS}

ANDREWS, J.C. O stress nos professores de Educação Física dos nossos dias: uma perspectiva internacional. Boletim da Sociedade Portuguesa em Educação Física, Lisboa, n.7/8, p.13-25, 1993.

Movimento, Porto Alegre, v. 15, n. 02, p. 169-186, abril/junho de 2009. 
BAUER, J. et al. Correlation between burnout syndrome and psychological and psychosomatic symptoms among teachers. International Archives Occupational Environmental Health, Berlin/Heidelberg, n.79, p.199-204, 2006.

BRAGGER, J.D. et al. Work-family conflict, work-family culture, and organizational citizenship behavior among teachers. Journal of Business and Psychology, Charlotte, n.20, v.2, p.303-324, 2005.

CARLOTTO, M.S.; PALAZZO, L.S. Síndrome de burnout e fatores associados: um estudo epidemiológico com professores. Caderno de Saúde Pública, Rio de Janeiro, v.22, n.5, p.1017-1026, 2006.

CARVALHO, L.M. O estudo da socialização dos professores em Educação Física: uma revisão e um convite. Boletim da Sociedade Portuguesa de Educação Física, Lisboa, n.13, p.11-37, 1996a.

CARVALHO, M.P. Trabalho docente e relações de gênero. Revista Brasileira de Educação. Rio de Janeiro, n.2, mai/jun/jul/ago, p.77-84, 1996b.

CASTRO, F. Sofrimento psíquico no trabalho. Revista Plural, Florianópolis, p.3446, jun. 2005.

CHIU, T.W. et al. A study on the prevalence of and risk factors for neck pain in secondary school teachers. Public Health, London, n.120, p.563-565, 2006.

CHIU, T.T.W.; LAM, P.K.W. The prevalence of and risk factors for neck pain and upper limb pain among secondary school teachers in Hong Kong. Journal Occupational Rehabilitation, Bethesda, n.17, p.19-32, 2007.

CORRIGAN, D.C.; HABERMAN, M. The context of teacher education. In: HOUSTON, W.R.; HABERMAN, M.; SIKULA, J. (Org.). Handbook of research on teacher education. New York: Macmillian, 1990.

CRUZ, R.M.; LEMOS, J.C. Atividade docente, condições de trabalho e processos de saúde. Motrivivência, Florianópolis, v.17, n.24, p.59-80, 2005.

DELCOR, N.S. et al. Condições de trabalho e saúde dos professores da rede particular de ensino de Vitória da Conquista, Bahia, Brasil. Caderno de Saúde Pública, Rio de Janeiro, v.20, n.1, p.187-196, 2004.

DORMAN, J.P. Relationship between school and classroom environment and teacher burnout: a LISREL analysis. Social Psychology of Education, Dordrecht, n.6, p.107$127,2003$.

DUBAR, C. A sociabilização: construção das identidades sociais e profissionais. Porto: Porto Editora, 1997.

GARCIA, C.M. Formación del profesorado para el cambio educativo. BarceIona: EUB, 1995.

Movimento, Porto Alegre, v. 15, n. 02, p. 169-186, abril/junho de 2009. 
GASPARINI, S.M.; BARRETO, S.M.; ASSUNÇÃO, A.A. O professor, as condições de trabalho e os efeitos sobre sua saúde. Educação e Pesquisa, São Paulo, v.31, n.2, p.189-199, 2005.

GATTI, B.A. Formação de professores e carreira: problemas e movimentos de renovação. Campinas: Autores Associados, 1997.

GRILLO, M.H.M.M.; PENTEADO, R.Z. Impacto da voz na qualidade de vida de professore(a)s do ensino fundamental. Pró-Fono: Revista de Atualização Científica, Barueri, v.17, n.3, p.321-330, 2005.

HOPF, A.C.O. Fico ou vou embora? Os sentimentos expressos por professores diante da aposentadoria. Revista da Educação Física/UEM, Maringá, v.13, n.2, p.89-96, 2002

JIMÉNEZ, B.M.; HERNÁNDEZ, E.G.; GUTIÉRREZ, J.L.G. La evaluación del estrés y el burnout del profesorado: el CBP-R. Revista de Psicología del Trabajo y las Organizaciones, Madrid, v.16, n.1, p.331-349, 2000

LACAZ, F. Trabalho e saúde do professor. Revista Plural, Florianópolis, p.14-19, jun. 2005

LAPO, F.R.; BUENO, B.O. Professores, desencanto com a profissão e abandono do magistério. Cadernos de Pesquisa, Campinas, n.118, p.65-88, 2003.

LEMOS, C.A.F. Qualidade de vida na carreira profissional de professores de Educação Física do magistério público estadual/RS. 2007. 102 f. Dissertação (Mestrado) - Curso de Educação Física, Centro de Desportos, UFSC. Florianópolis, 2007.

LEMOS, J.C.; CRUZ, R.M. Condições e cargas de trabalho da atividade docente. Revista Plural, Florianópolis, p.20-27, jun. 2005.

LÜDKE, M.; BOING, L.A. Caminhos da profissão e da profissionalidade docentes. Revista Educação e Sociedade, Campinas, v.25, n.89, p.1159-1180, 2004.

MONTEIRO, J.E.S. As instalações em Educação Física: romper o estrangulamento. Boletim da Sociedade Portuguesa de Educação Física, Lisboa, n.7/8, p.3547, 1993.

MONTEIRO, J.E.S. As instalações e os equipamentos para a Educação Física no $1^{\circ}$ ciclo do ensino básico. Boletim da Sociedade Portuguesa de Educação Física, Lisboa, n.14, p.55-64, 1996a.

MONTEIRO, J.E.S. Caracterização das instalações da Educação Física escolar. Boletim da Sociedade Portuguesa de Educação Física, Lisboa, n.13, p.67$88,1996 b$.

NEVES, A.; RODRIGUES, G.; SOBRAL, F. Avaliação subjetiva do stress profissional: resultados de um inquérito preliminar em professores de Educação Física. Boletim da Sociedade Portuguesa de Educação Física, Lisboa, n. 7/8, p.27-34, 1993.

Movimento, Porto Alegre, v. 15, n. 02, p. 169-186, abril/junho de 2009. 
NILAN, P. Teachers' work and schooling in Bali. International Review of Education, Hamburb, v.49, n.6, p.563-584, 2003.

NÓVOA, A. Formação de professores e profissão docente. In: NÓVOA, A. (Org.). Os professores e a sua formação. Lisboa: Dom Quixote. 1995a.

NÓVOA, A. O passado e o presente dos professores. In: NÓVOA, A. (Org.). Profissão professor. Porto, Porto Editora. 1995b.

PACHECO, J.A.; FLORES, M.A. Formação e avaliação de professores. Porto: Porto Editora, 1999.

PENTEADO, R.Z.; PEREIRA, I.M.T.B. Qualidade de vida e saúde vocal de professores, Revista de Saúde Pública, São Paulo, v.41, n.2, p.236-243, 2007.

PORTO, L.A. et al. Associação entre distúrbios psíquicos e aspectos psicossociais do trabalho de professores. Revista de Saúde Pública, São Paulo, v.40, n.5, p.818-826, 2006.

REIS, E.J.F.B. et al. Docência e exaustão emocional. Educação e Sociedade, Campinas, v.27, n.94, p.229-253, 2006.

RODRIGUES, A.L. Estresse e trabalho: aumenta a preocupação com o desgaste do trabalhador. Revista Proteção, São Paulo, v.17 n.4, p.38-41, 1992.

SANTINI, J. Diagnóstico na Educação Física: Síndrome do Esgotamento Profissional (SEP). Corpo e Movimento, Canoas, v.2, n.1/2, p.17-29, 2004a.

Síndrome do Esgotamento Profissional: revisão bibliográfica. Movimento, Porto Alegre, v.10, n.1, p.183-209, 2004b.

SANTINI, J.; MOLINA NETO, V. A Síndrome do Esgotamento Profissional em professores de Educação Física: um estudo na rede municipal de ensino de Porto Alegre. Revista Brasileira de Educação Física e Esporte, São Paulo, v.3, n.19, p.209222, 2005.

SOUSA, J.L.C. Aula de Educação Física: o que o professor sente e pensa. Boletim da Sociedade Portuguesa de Educação Física, Lisboa, n.28/29, p.77-87, 2004.

. Condição docente: fatores de bem-estar no exercício profissional. Boletim da Sociedade Portuguesa de Educação Física, Lisboa, n.7/8, p.49-59, 1993.

TEODORO, A. Da profissionalização da actividade docente à crise de identidade dos professores: considerações preliminares para um estudo da situação portuguesa. Boletim da Sociedade Portuguesa de Educação Física, Lisboa, n.9, p.37-54, 1994.

Recebido em: 29.02.2008

Aprovado em: 16.02.2009

Movimento, Porto Alegre, v. 15, n. 02, p. 169-186, abril/junho de 2009. 